\title{
Low-head hydropower energy resource harvesting: analysis and design of a Venturi turbine
}

- Nadipuram R. Prasad

- Satish J. Ranade

New Mexico State University, Las Cruces, USA

- Phuc Huu Nguyen

Ho Chi Minh city University of Technology, VNU-HCMC, Vietnam

(Manuscript Received on July 15, 2015, Manuscript Revised August 30, 2015)

\begin{abstract}
The paper provides a low-head hydropower energy resource harvester (HyPER) design of 4-blade impeller with a fixed pitch blade angle. Based on a previous site evaluation and maximum power potential estimated without any modifications to the irrigation structure, the proposed objective of exploiting the estimated power will be met from harvester prototypes with portable, compact modular design. This makes

assembly easy, uses off-the-shelf components to produce power. Calculations were carried out for designing guidevanes, Venturi tube, impeller blades and Computational Fluid Dynamics (CFD) software then is used in verifying the design. Designed as a self-supporting structure, the configuration offers a scalable hydropower generating system suitable for low-head drops along irrigation canals.
\end{abstract}

Keywords: computational fluid dynamics, harvester system, low-head Venturi turbine, turbine impellers.

\section{INTRODUCTION}

In some countries, where a considerable portion of the electric power produced comes from conventional hydropower plants to meet the annual growth of electricity, there appears little regard placed by developers towards environmental and ecological consequences. Medium and small-sized hydro power plants are built on any power-potential river flows, with unprecedented detrimental consequences. Dams and other infrastructure continue to severely damage the open environment and simultaneously upset local economic development of the region. While high-head and high-flow waterway systems

have been exploited to nearly their critical limit, low-head hydropower systems remain to be explored for sustainable power generation. In sharp contrast with high-head hydropower and the so bad consequences of its exploitation on the environment, low-head systems do not require large infrastructures, and can be installed, operated and maintained easily and are minimally invasive. The HyPER harvester shown in Figure 1 is a complete hydropower system that can be easily manufactured and assembled and therefore can be deployed at sites with minimal infrastructure to harvest energy. The paper 
introduces a harvester design concept based on two fundamental criteria, namely, $i$ ) the maximum power generating capacity at the site, and ii) the specific speed characteristics of a turbine which will produce the desired power output. Designed as a self-supporting structure, the configuration offers a scalable hydropower generating system suitable for low-head drops along irrigation canals.

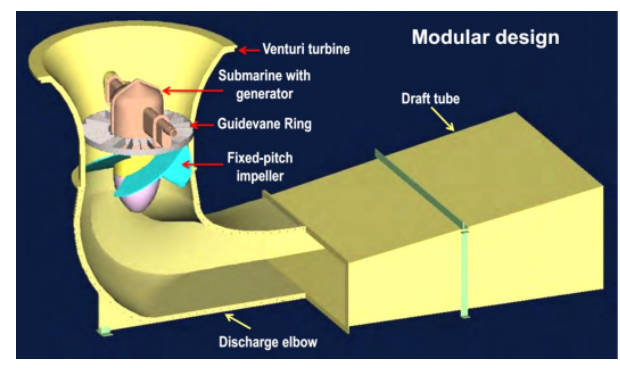

Figure 1. Low-head hydropower harvester

\section{HARVESTER DESIGN BASIS AND CFD SIMULATIONS}

Previous computational fluid dynamic studies have shown the harvestable capacity of the Drop 8 at the Elephant Butte Irrigation District (EBID), without any modifications to the historic structure, is approximately $50 \mathrm{~kW}$, per drop [1]. An additional $20 \mathrm{~kW}$ generation from the kinetic energy harvested from diffuser action yields the maximum capacity of each drop.

\subsection{Anticipated Hydropower Recovery at Ebid Drop 8 Structure}

Preliminary design parameters for hydropower begin by taking the known parameters of a site, namely discharge and pressure head, and computing a specific speed. Based upon a theoretical estimate of shaft torque and RPM, the task then is to choose an appropriate generator such that the plant would operate at its best efficiency point. There is a large body of literature for computing specific speed for conventional, large hydropower plant design [2], [3]. However, for micro-hydro there is very little information regarding low-head performance of axial-flow reaction turbines [4], [5], [6].

There are several specific speed formulas and charts suggested to obtain a set of preliminary design parameters [2], [3].

A remarkable empirical formula developed by Schweiger and Gregory [2] yields the relationship between specific speed $N_{s p}$ and pressure head $H$ for head less than 2.5 meter, given by $N_{s p}=2.294 / H^{0.486}$ (1). US Bureau of Reclamation Water Operations (USBR) suggests $N_{s p}=2.716 / H^{0.5}$, which yields approximately 14 $18 \%$ higher figures than (1).

At the Drop 8 irrigation structure, the head can vary between a maximum of 2.22 meters to a minimum when the power generation naturally subsides towards the tail-end of the irrigation season. Around $1 \mathrm{~m}$ is assumed as the minimum pressure head to continue producing power. From a design perspective, this head would be approximately equal to the length between the Venturi inlet and the impeller. The impeller is approximately 1 meter below the drop when the reservoir is full and water is at the maximum height of 1.22 meters above the drop. During lowflow conditions the head above the drop inside the reservoir is small. Variation in the effective head above an impeller is illustrated in Figure 2.

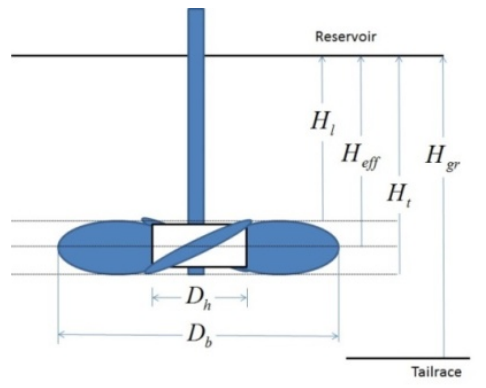

Figure 2. Head above the impeller

The specific speed versus head empirical relationship for the expected range of pressure head variation is illustrated in Figure 3. The actual discharge from the orifice depends on the cavity 
formed by the Venturi-turbine and the submarine assembly in the flow path. The actual maximum discharge obtained from simulations carried out in Computational Fluid Dynamics (CFD) ANSYS software platform yields the mass-flow rate through the harvester $M=3,500 \mathrm{~kg} / \mathrm{s}$. Based on this discharge the amount of power that can be harvested is calculated.

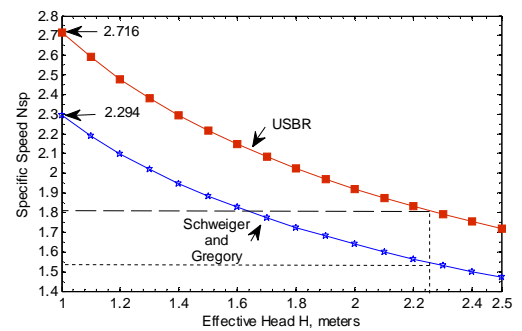

Figure 3. Specific Speed vs Head

With a gross head $H_{g r}=2.22 \mathrm{~m}$ (from water surface in the reservoir to the water surface in the tail race), and assuming the efficiency $\eta=80 \%$, the available power $P_{\text {avail }}=\eta \rho Q g H_{g r}=61 \mathrm{~kW}$. Based on the specific speed and the available power, the shaft speed is determined [2]:

$$
N=\frac{N_{s p}(g H)^{1.25}}{\sqrt{P_{\text {avail }}}}
$$

At a pressure head of 2.22 meters, the specific speed:

$$
N_{s p}=\frac{2.294}{H^{0.486}}=1.557
$$

With approximately $61 \mathrm{~kW}$ of available power, the shaft speed $N=563$ RPM. Figure 4 shows the range of shaft speed and available power considering change in the effective head in the range of 0.5-2.5 m, with an energy conversion efficiency of $90 \%$. Figures 5 and 6 show the relationships of shaft speed versus head and available power versus discharge, respectively.
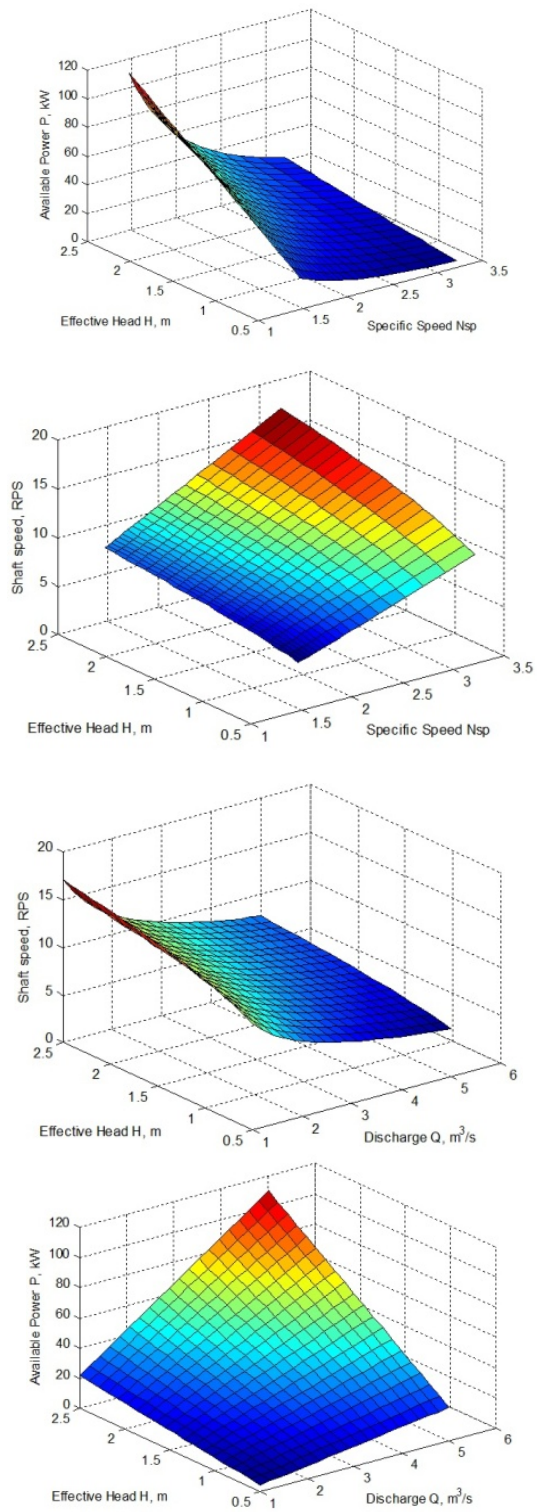

Figure 4. Shaft speed and Available power vs effective head and discharge

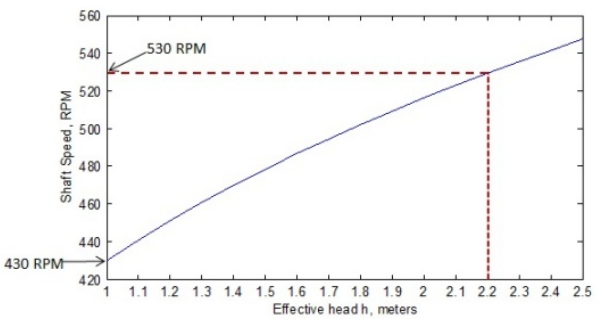

Figure 5. Shaft speed vs head

\section{Trang104}




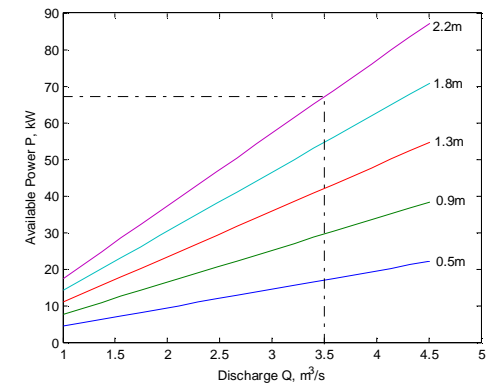

Figure 6. Available power vs discharge

\subsection{Hub-Tip Ratio in Harvester Design}

An empirical formula suggested by [6] to compute the runner diameter:

$$
D_{\text {Runner }}=84.5\left(0.79+1.602 N_{s p}\right) \frac{\sqrt{H_{\text {Effective }}}}{60 * \Omega}
$$

where $\Omega$ is the angular velocity in rads/s.

For an effective head of $2.22 \mathrm{~m}$, the specific speed is 1.557 . The design concept is to adapt the size of the Venturi turbine to any suitable commercially available, off-the-shelf generating component. As such, the basis to select the throat diameter of the Venturi is the overall diameter of the "best" suited generator for the specific application.

This is a major criteria for assembling offthe-shelf generators.

The design considers two possible hub-tip ratios, namely 0.3 and 0.42 , that has been investigated and reported in [1]. The hub diameter is based on the overall diameter of the generator. In this case, the selection of a low-speed high torque permanent magnet alternator provides the overall diameter. The submarine shell which encloses the generator is optimized for a close fit. The hub diameter, therefore, is the overall diameter of the submarine enclosure. Figure 7 shows the relative size of the submarine in relation to the hub. Proper selection of the hub-tip ratio then yields the throat diameter of the Venturi.

The constraint posed by Drop 8 is the height of the Venturi. This height must fit the gap between the concrete cylindrical gates above the drops and the floor of the reservoir. As such, the Venturi is designed as a half-hyperboloid and the conical diffusor portion of the Venturi is made part of entry to the suction tube elbow.

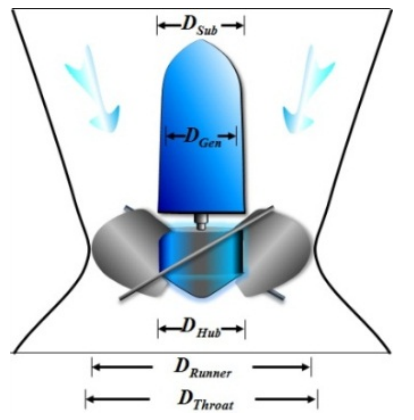

Figure 7. Hub-to-Runner ratio

$$
\begin{aligned}
& D_{\text {Hub }}=D_{\text {Sub }} D_{\text {Hub }} / D_{\text {Runner }}=0.3 \text { or } 0.42 \\
& D_{\text {Throat }}=D_{\text {Runner }}+\Delta D
\end{aligned}
$$

$\Delta D / 2$ is the gap between the impeller tip and the Venturi wall. This gap will be approximately 3.17- $6.34 \mathrm{~mm}$. Naturally, for small hub-tip ratios the blade area is large and the diameter of the Venturi outlet will increase. Conversely, as the ratio increases the effective blade area decreases.

For a hub-tip ratio of 0.42 , the hub diameter is $D_{h}=0.32 \mathrm{~m}$, and the following parameters are calculated:

Blade diameter $D b=0.762 \mathrm{~m}$,

Axial fluid velocity

$V_{a}=\frac{Q}{A_{\text {blade }}}=\frac{4 * \dot{M}}{\rho * \pi *\left(D_{b}^{2}-D_{h}^{2}\right)}=9.32 \mathrm{~m} / \mathrm{s}$.

Blade angular velocity $U=\omega r=2 \pi N$ $D_{b} / 2=\pi N D_{b}==21.26 \mathrm{~m} / \mathrm{s}$,

Head at leading edge of blade $H_{l}=1.8 \mathrm{~m}$,

Tangential velocity at the leading edge $V_{t l}=\left(g H_{l}\right) / U=0.83 \mathrm{~m} / \mathrm{s}$,

Head at trailing edgeof blade $H_{t}=2.22 \mathrm{~m}$,

Tangential velocity at the trailing edge $V_{t t}=$ $\frac{g H_{t}}{U}=1.024 \mathrm{~m} / \mathrm{s}$,

Shaft Torque $\tau=\dot{M}\left(V_{t t} r_{t}-V_{t l} r_{l}\right)=$ $\dot{M} \frac{D_{b}}{2}\left(V_{t t}-V_{t l}\right)=258.40 \mathrm{Nm}$, 
Shaft power $P_{\text {shaft }}=\omega \tau=2 \pi N \tau=14.42 \mathrm{~kW}$

Results indicate hardly any changes in power output between the two hub-tip ratios of 0.3 or 0.42 considered. The torque-speed characteristic for hub-tip ratio of 0.42 is shown in Figure 8.

From a physical size perspective, a smaller hub-to-tip ratio increases the runner diameter and hence the throat diameter of the Venturi. This makes the inlet of the suction tube and elbow to be larger in size and conflict with the physical constraints of the Drop 8 structure. A larger diameter impeller weighs more, and costs more. With physical constraints where there is no possibility for structural modification, an optimal size must be selected. As such, the design is based on a hub-tip ratio of 0.42 , as it makes the harvester fit better at the Drop 8 site, while providing sufficient margin for implementing successfully.

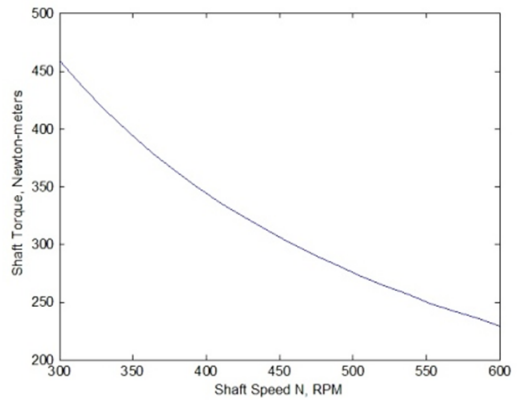

Figure 8. Torque vs Shaft speed for a hub-tip ratio of 0.42

\subsection{Guidevanes Design}

Guide vanes are used to enhance the swirl of the flow approaching the impeller blades. The impeller blades change the tangential velocity component of the flow, and it is this change in tangential momentum that produces the torque that drives the generator. There is also an axial component of force on the blades, produced by the pressure differential across the blades. If the swirl or tangential velocity component given to the flow by the guide vanes balances the change in tangential velocity through the blades, the flow will leave the blades with zero tangential velocity, i.e., the flow will be purely axial. Theoretically, this is the most efficient operating point since the tangential velocity cannot be recovered as a pressure drop in the draft tube. However, some exit swirl may cause improved performance, for example the flow may follow the diverging draft tube walls better. If the change in tangential velocity through the blades is not large the increase in efficiency with guide vanes fitted may not justify the extra complications in manufacture, i.e., the turbine could be made with a simpler inlet structure. For ease in fabrication, the guide vanes are oriented at an angle of 90 o to the blade angle.

\subsection{Impeller Design}

The runner is the rotating part of the turbine and includes the hub, blades and shaft. The objective in the harvester design is to minimize the manufacturning cost by simplifying the design features. The use of flat blades with a slight curvature at the tip is easier to manufacture than a curved blade with complex surface geometry. In light of this, a 4-blade impeller with a fixed pitch blade angle is chosen for design. While typically the impeller is made of steel, it could be fabricated as a Carbon composite molding due to its lightweight. However, fabricating the negative mold might not be cost-effective. The mechanical engineering design review recommends the impeller to be made of cast ASTM A743 Steel CA6NM and fabricated as a single piece using a 5-axis CNC machine. Having high impact strength, an iron-chromium-nickel-molybdenum alloy Type CA6NMis resistant to cavitation effects and erosion from silt in the water.

Ideally, the blade angles at their leading and trailing edges should match the relative flow direction at all radii. This would require complicated curvature of the blades for a non-free vortex approach flow. The blade angle should change from leading to trailing edge and with varying radius. Employing flat blades gives the turbine greater range of application possibilities, since the manufacture would be less complicated.

\section{Trang 106}


The runner could be easily fabricated with commonly available machine-shop tools.

The ideal change in angle from leading edge to trailing edge is determined by the change in tangential velocity component that is required. Referring to Figure 9, from the velocity triangle for a flow having axial and tangential velocity components $V_{\text {Axial }}$ and $V_{\text {Tan }}$, the angle of the flow observed relative to a blade moving with tangential velocity $\beta$, is given by:

$$
\tan \beta=\frac{V_{\text {Axial }}}{r \omega-V_{\text {Tan }}}
$$

where, $V_{\text {Axial }} \sim Q / A, Q$ is the discharge and $A$ is the area of cross-section at the throat of the Venturi.

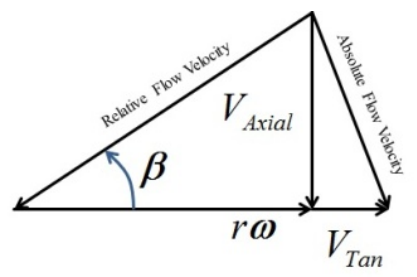

Figure 9. Velocity triangle for blade angle estimation

$V_{T a n}$ is calculated from the change in tangential momentum that yields the required power output. By equating the power produced by the turbine to the rate of change of momentum yields: $\eta \rho Q g h=\rho Q \Delta V_{T a n}$ (3)

Assuming $V_{\text {Tan }}=0$ at the trailing edge so that there is no swirl at the outlet, the leading edge velocity $V_{T a n}=\Delta V_{T a n}(4)$

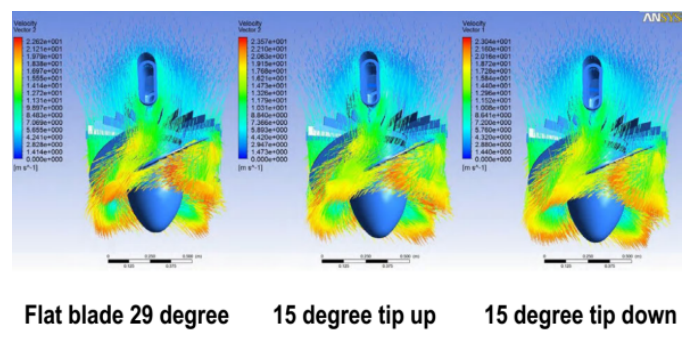

Figure 10. CFD flow simulations at different blade angles

The condition assumed in (4) is a simplification to obtain the ideal blade angle.
While the swirl created by the trailing edge of the blade must be a minimum, it is reasonable from a manufacturing viewpoint to adopt a flat blade with a curved tip. The design is to place flat blades at an angle of $30^{\circ}$ with the tips curved up at $15^{\circ}$ as shown from CFD simulations in Figure 10.

Substituting (4) in (3) yields $V_{T a n}=\eta g h / r \omega$, which is the swirl velocity introduced by the guidevanes on the runner. Given an impeller configuration, the effective blade area is computed as:

$$
A=\pi \frac{\left(D_{\text {Runner }}^{2}-D_{H u b}^{2}\right)}{4}=\frac{\pi}{4} D_{\text {Runner }}^{2}\left[1-\frac{D_{\text {Hub }}^{2}}{D_{\text {Runner }}^{2}}\right]
$$

For a set of typical values: $\eta=0.9, h=2.22 \mathrm{~m}$, $Q=3.5 \mathrm{~m} 3 / \mathrm{s}, D_{\text {runner }}=0.762 \mathrm{~m}, D_{H u b} / D_{\text {Runner }}=0.42$

$A=0.3756 \mathrm{~m}^{2}, r=0.381 \mathrm{~m}, N=430 \mathrm{RPM}, \omega=$ $45.03 \mathrm{rad} / \mathrm{s}$

Axial velocity is approximated by: $V_{\text {Axia }} \approx$ $Q A /=9.32 \mathrm{~m} / \mathrm{s}$ and Tangential velocity $V_{T a n}=$ $\eta g h / r \omega=1.14 \mathrm{~m} / \mathrm{s}$.

$\beta$ can be determined as $30.2^{\circ}$ angle with respect to the shaft axis.

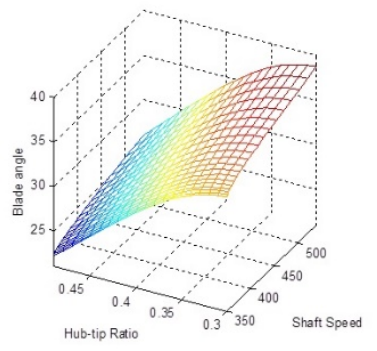

Figure 11. Blade angle as a function of shaft speed

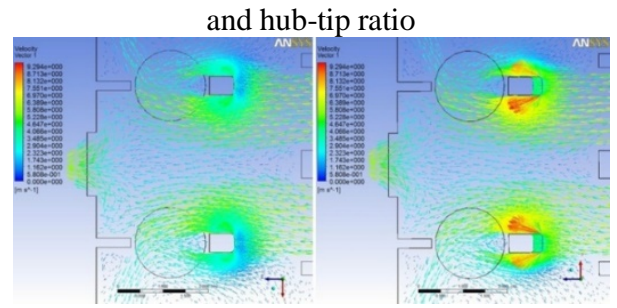

Figure 12. Velocity vectors showing swirl at top surface of water in reservoir above drops 
The plot showing blade angle as a function of shaft speed and hub-tip ratio in Figure 11 reveals that the maximum blade angle is $38.6^{\circ}$ over the range of shaft speed of interest. For a hub-tip ratio of 0.42 , the best angle is approximately $30^{\circ}$.

CFD simulation results in Figure 12 show that the two drops have vortex flow. Because of the structural symmetry, as water enters the inlet gates and flows towards the drops, the flows form swirls in opposite directions. This is important to note because the water that is entering the Venturi has a significant swirl velocity. The cavity formed by the Venturi and submarine is such that flow entering the hyperboloid shaped duct continues to swirl at higher velocity as it exits the Venturi throat. The shape of the Venturi, therefore, aids water discharge through the harvester at high velocity. Simulation shows swirl velocity around $8 \mathrm{~m} / \mathrm{s}$ at the inlet of both drops.

In order to take advantage of the higher velocity produced by vortex flow, the impeller motion of each harvester is set to occur in the same direction as the swirl. Guidevanes in each harvester are mounted so as to allow the water to impinge on the leading edge of the blades at maximum velocity. This has the tendency to increase the shaft speed and hence increase the shaft torque.

\section{DESIGN SUMMARY AND BASELINE PARAMETERS}

The generating system employs a verticalaxis, axial-flow configuration to maximize the shaft torque, and hence the power generated by an impeller due to potential head. Similar to the classical Kaplan-turbine configuration, the Venturi-shaped, reaction-type turbine acts to impart hydraulic energy on a fixed-pitch impeller blade assembly placed at the throat of the Venturi. A suction tube elbow aids to create the desired potential drop across the impeller and to transform the hydraulic potential energy into rotational kinetic energy. The outlet is a conicallyshaped draft tube that helps to decelerate water entering the tailrace. This enables the recovery of kinetic energy as several cubic meters of water discharges through the harvester per second. The maximum estimated discharge through each drop at Drop 8 is $4.8 \mathrm{~m}^{3}$. A 24-pole, permanent magnet, variable-speed alternator with associated power converting hardwareis a suitable choice for power generation. Based on typical flow rates at Drop 8, the expected shaft speeds are in the range of 350550 RPM, and torque in the range of $400-255$ $\mathrm{Nm}$ (low-speed high torque and vice versa). This makes variable frequency alternators an economical choice as there is no speed control mechanism required.

Based on key scalable attributes of the harvester, the physical size of the harvester is customized to existing structures and satisfies critical design criteria that maximize the hydropower that can be recovered. Hub-to-tip ratio is the critical design parameter in impeller design. Based on calculation and simulation results, two complete prototypes of 4-blade fixedpitch impellers, one with $28^{\circ}-29^{\circ}$ blade angle, and the second with $33^{0}-34^{0}$ blade angle were designed, fabricated and installed at the site and ready for testing, as shown in Figure 13.
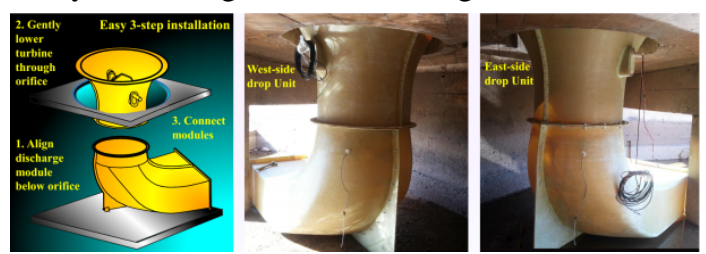

Figure 13. Harvesters installed at Drop 8

\section{CONCLUSIONS}

At the maximum efficiency of $94 \%$ (the efficiency of a variable-pitch propeller driven Kaplan turbine), CFD studies have shown the maximum harvesting potential is $27 \mathrm{~kW}$ without any modifications to the Drop 8 structure. 
However, with fixed blades while conversion efficiency can be as low as $75-80 \%$ there is sufficient confidence that the proposed objective of harvesting $20 \mathrm{~kW}$ will be met from two, $10 \mathrm{~kW}$ each, hydropower prototypes. Simplicity in design and packaging of elements leads to substantial cost reductions in manufacturing and assembling hydropower harvesters. A plug-andplay modular architecture makes the installation easy and helps in creating a robust market for a new generation of hydropower harvesting systems. The self-supporting structure lowers the LCOE thereby making it an affordable technology. With strong commercialization possibilities, the HyPER harvester holds promise towards its expanded use worldwide for hydropower generation from low-head water resources.

\section{Khai thác nguồn thủy năng cột áp thấp: phân tích và thiết kế turbine kiểu ống Venturi}

- Nadipuram R. Prasad

- Satish J. Ranade

New Mexico State University, Las Cruces, USA

- Nguyễn Hũu Phúc

Trường Đại học Bách Khoa, ĐHQG-HCM, Việt Nam

\section{TÓM TÁT}

Bài báo trình bày việc thiết kế một hệ phát thủy điện cột nước thấp với 4 cánh quạt có góc nghiêng cố định. Dựa trên các đánh giá trong bài báo trước về tiềm năng công suất lớn nhất của địa điểm mà không can thiệp vào cấu trúc của kênh tưới tiêu, mục tiêu đặt ra là khai thác tiềm năng công suất dòng chảy với các hệ thử nghiệm dễ di chuyển, gọn nhẹ với thiết kế dạng module. Điều này giúp cho việc lắp ráp được dễ dàng, và sử dụng các bộ phận sã̃n có trong sản xuất năng lượng. Các tính toán thiết kế cánh hướng dòng, biên dạng cánh quạt, ống Venturi đã được thực hiện, và sau đó phần 
mềm tính toán động lực lưu chất được dùng nâng cấp sẽ thích hợp cho các ưng dụng trên để kiểm chứng thiết kế. Với thiết kế tự ổn các kênh thủy lợi cột nước thấp.

định, hệ phát thủy điện có công suất dễ dàng

Từ khóa: động lực học tính toán dòng chảy, hệ sản xuất năng lượng, turbine Venturi cột nước thấp, cánh quạt turbine.

\section{REFERENCES}

[1]. Nadipuram R. Prasad, Satish J. Ranade, Hydropower Energy Resource (HyPER) Harvester; Department Of Energy 2014 Water Power Program Peer Review Compiled Presentations - HydroPower Technologies, Washington Feb 25-28, 2014.

[2]. Schweiger, F. and Gregory, J. ; Developments in the Design of Kaplan turbines; Water Power \& Dam Construction, Vol. 39, \#11, Nov. 1987, pp 16-20.

[3]. Sadek, R. and Sinbel, M. A.; Water Turbines and Dimensional Analysis; Water Power Vol. 12, \#10, Oct. 1960, pp 381-389.

[4]. "Micro-hydropower: Reviewing an old concept" DOE/ET/01752-1, January 1979 http://hydropower.inel.gov/techtransfer/pdfs/ doe-et-01752-1.pdf.

[5]. Boucher, P. J. "Chutes-de-la-Chaudiere: optimizing hydraulic potential, enhancing natural beauty" Hydro Review, Vol. XX, \#4, July 2001, pp. 76-80.

[6]. Gordon, J. L. "Turbine selection for small low-head hydro developments", Unknown publishing date. http://www.hallandsvkrf.se/litteratur/worksh

ops/Turbine $\% 20$ selection $\% 20$ for $\% 20$ small\% 20low\%20head\%20hydro.pdf

[7]. Kai-Wern Ng, Wei-Haur Lam, Khai-Ching Ng.; 2002-2012: 10 Years of Research Progress in Horizontal-Axis Marine Current Turbines; Energies 2013, 6, 1497-1526; doi:10.3390/en6031497.Mahrez AitMohammed, Mostapha Tarfaoui, Jean Marc Laurens; Predictions of the Hydrodynamic Performance of Horizontal Axis Marine Current

[8]. Ram Prasad, Phuc Huu Nguyen; Hydropower Energy Recovery (HyPER) from Water-Flow Systems in Vietnam, Proceedings of the 10th IEEE International Power and Energy Conference (IPEC 2012- Ho Chi Minh City); HoChiMinh City Dec 12-13, 2012.

[9]. John F. Wendt (Ed.) and al.; An introduction to Computational Fluid Dynamics, Third Edition, Springer- Verlag 2009.

[10].Nadipuram R. Prasad, Satish J. Ranade, Phuc Huu Nguyen, Low-Head Hydropower Energy Resource Harvesting: Estimation of Maximum Harvestable Power, Paper submitted to ISEE 2015, Oct 2015 HoChiMinh City, VietNam. 